JOSETA: Journal of Socio Economic on Tropical Agriculture

Volume 1 Nomor 1: 97-103 April (2019)

JOSETA: Journal of Socio Economic on Tropical Agriculture http://joseta.faperta.unand.ac.id

ISSN : $2686-0953$ (online)

\title{
Faktor-Faktor Yang Mempengaruhi Produksi Kakao Rakyat Di Kabupaten Tanah Datar (Studi Kasus di Nagari Balimbing Kecamatan Rambatan, Kabupaten Tanah Datar)
}

\author{
Sherly Ananda ${ }^{1}$, Rahmat Syahni ${ }^{1}$, Rusda Khairati ${ }^{1}$ \\ ${ }^{1}$ Jurusan Sosial Ekonomi Fakultas Pertanian Unand, Padang, indonesia \\ Email: rsyahni@yahoo.com \\ Received: $20^{\text {th }}$ Februari, 2019; $1^{\text {st }}$ Revision: $10^{\text {th }}$ Maret, 2019; $2^{\text {nd }}$ Revision: $2^{\text {th }}$ April, 2019 Accepted: $17^{\text {th }}$ April, 2019
}

\begin{abstract}
Nagari Balimbing is one of the cocoa model nagari located in Rambatan Sub-district, Tanah Datar District. Recently, the level of cocoa productivity in Nagari Balimbing is still low, only between 0.9 to 1 ton/ha, still far from its potential production 2.5 ton/ha. The objectives of this study are to describe the cultivation of cocoa and factors that influence cocoa production in Nagari Balimbing. The data was collected from 40 farmers which were selected using stratified random sampling from the cocoa farmers in Nagari Balimbing. The data was analyzed by multiple regression analysis using Cobb Douglass production function. Variables used in this study were cocoa production as dependent variable and land area, labor, manure and phonska fertilizer as independent variables. The results showed that the chocolate production in Nagari Balimbing is influenced jointly by land area and labor with determination coefficient $98.2 \%$. While manure and phonska do not affect the cocoa production significantly.
\end{abstract}

Keywords : Cocoa Model Nagari, Production Factor, Cocoa Production

\section{PENDAHULUAN}

Subsektor perkebunan memiliki peranan penting dalam menunjang devisa negara karena beberapa komoditi perkebunan memiliki perolehan devisa yang tinggi. Jenis komoditi perkebunan yang diekspor Indonesia antara lain adalah kakao, karet, kelapa, kelapa sawit, kopi, panili, tebu, teh dan tembakau. Kakao (Theobrema cacao L.) merupakan salah satu komoditas perkebunan yang peranannya cukup penting bagi perekonomian nasional, khususnya sebagai penyedia lapangan pekerjaan, sumber pendapatan dan devisa negara. Disamping itu kakao juga berperan dalam mendorong pengembangan wilayah dan pengembangan agroindustri.

Selama tahun 1980-2013 pertumbuhan rata-rata produksi kakao meningkat sebesar 3,34\% per tahun. Tahun 1980 produksi kakao dunia sebesar 1,67 juta ton kemudian pada tahun 2013 meningkat menjadi 4.59 juta ton. Perkembangan volume ekspor dan volume impor kakao di dunia pada periode 1980-2013 mengalami peningkatan dengan rata-rata pertumbuhan 3,59\% pertahun untuk volume ekspor dan 3,34\% per tahun untuk volume impor. Pada tahun 1980 volume ekspor kakao sebesar 1,06 juta ton dan tahun 2013 menjadi 2,72 juta ton. Sementara untuk volume impor tahun 1980 sebesar 1,07 juta ton dan tahun 2013 menjadi 2,94 juta ton (Kementrian Pertanian, 2016).

Sumatera Barat telah dicanangkan menjadi sentra produksi kakao untuk wilayah Indonesia Bagian Barat sejak tanggal 3 Agustus 2008 yang diharapkan dapat berperan sebagai penyangga terhadap penurunan produksi kakao di sentra-sentra produksi Wilayah Timur Indonesia. Hal ini didukung dengan 
adanya program revitalisasi perkebunan (Disbun Sumbar, 2009). Program revitalisasi perkebunan merupakan suatu upaya percepatan pengembangan perkebunan rakyat melalui perluasan, peremajaan dan rehabilitasi tanaman perkebunan yang didukung kredit investasi perbankan dan subsidi bunga oleh pemerintah dengan melibatkan perusahaan di bidang usaha perkebunan sebagai mitra pengembangan dalam pembangunan kebun, pengolahan dan pemasaran hasil dengan tiga komoditas yaitu kelapa sawit karet dan kakao (Ditjenbun, 2007).

Kabupaten Tanah Datar sebagai salah satu sentra produksi kakao di Sumatera Barat, dewasa ini merupakan salah satu daerah pengembangan kakao yang potensial di Sumatera Barat (Badan Pusat Statistik, 2013). Perkembangan luas lahan kakao selama 5 tahun terakhir di Kabupaten Tanah Datar mengalami peningkatan, terakhir di tahun 2016 luas lahan kakao adalah sebesar 4.050,00 ha. Perkembangan produksi kakao di Kabupaten Tanah Datar dari tahun 2012 sampai tahun 2015 terus mengalami peningkatan. Namun pada tahun 2016 mengalami penurunan dari 3.821,65 ton tahun 2015 menjadi 3.787,37 ton tahun 2016. Produktivitas kakao juga mengalami penurunan pada tahun 2016 (BPS Kabupaten Tanah Datar, 2017).

Kendala utama dalam pengembangan kakao di Kabupaten Tanah Datar adalah produksi yang masih jauh dari potensi produksi yang dapat dicapai. Saat ini rata-rata produksi kakao pertahun yang dihasilkan oleh sekitar 0,9-01 ton /ha, masih jauh dari potensinya yang bisa mencapai 2,5 ton/ha bila menerapkan teknologi perkakaoan secara optimal (Puslitkoka, 2013). Meskipun ada sebagian kecil petani mencapai produksi yang dihasilkan melampaui potensinya, namun secara rata-rata masih jauh dari harapan sehingga perlu upaya peningkatan dalam produksinya.

Nagari Balimbing adalah salah nagari yang berada di Kecamatan Rambatan Kabupaten Tanah Datar yang merupakan salah satu nagari model kakao (NMK) yang dicanangkan oleh Gubernur Sumatera Barat pada tahun 2010. NMK merupakan program pengembangan desa/nagari mandiri kakao, yang dicanangkan secara komprehensif dan terintegrasi sesuai dinamika permasalahan yang dihadapi, melibatkan berbagai pihak melalui dukungan dan fasilitasi banyak pihak, sehingga melalui NMK diharapkan komoditas kakao bisa menjadi motor penggerak ekonomi nagari dalam upaya mewujudkan masyarakat sejahtera.

Dari survei pendahuluan yang telah dilakukan sampai saat ini tingkat produksi kakao di Nagari Balimbing masih rendah jauh dari potensinya yang bisa mencapai $2500 \mathrm{~kg}$. Tanaman kakao di Nagari Balimbing hanya mampu berproduksi antara 900-1000 kg, sedangkan lahan yang tersedia masih banyak yang belum digunakan sehingga perlu upaya untuk peningkatan produksinya. Rendahnya produksi tanaman kakao dapat disebabkan oleh penggunaan faktor produksi yang belum optimal sehingga berakibat menurunnya produktivitas. Faktor-faktor produksi dalam usaha tani kakao menurut Kristanto (2011) adalah lahan, modal, tenaga kerja, pupuk, bibit, dan pestisida. Demikian juga teknik budidaya tanaman yang masih rendah seperti pemupukan, pemangkasan, sanitasi dan pengendalian organisme pengganggu tanaman (OPT). Diantara jenis hama dan penyakit yang sering menyerang tanaman kakao antara lain adalah hama penggerek buah kakao, kepik penghisap buah kakao dan penyakit busuk buah.

Berdasarkan permasalahan diatas, telah dilakukan penelitian untuk menjawab pertanyaan tentang bagaimana penerapan budidaya kakao dan faktor apa yang mempengaruhi produksi kakao di Nagari Balimbing Kabupaten Tanah Datar. Tujuan penelitian ini adalah mendeskripsikan bagaimana usahatani kakao di Nagari Balimbing dan mengetahui faktor produksi yang mempengaruhi produksi kakao di Nagari Balimbing Kabupaten Tanah Datar.

\section{METODE PENELITIAN}

Penelitian ini dilakukan di Nagari Balimbing Kabupaten Tanah Datar dengan pertimbangan bahwa Nagari Balimbing merupakan salah satu daerah pengembangan kakao yang potensial, merupakan Nagari Model Kakao di Kabupaten Tanah Datar, dan belum adanya penelitian khusus mengenai faktor yang mempengaruhi produksi kakao di Nagari Belimbing. Penelitian ini dilaksanakan selama 1 bulan dari bulan Maret sampai bulan April 2018.

Pengambilan sampel dilakukan pada dua jorong secara proporsional dengan metoda Proportionated Stratified Random Sampling (teknik acak berstrata proporsional), yaitu teknik pengambilan sampel yang dilakukan apabila sifat atau unsur dalam populasi tidak homogen dan berstrata secara proporsional 
(Sugiyono, 2015). Penentuan jumlah sampel pada penelitian ini menggunakan rumus Slovin sebagai berikut:

$$
\mathrm{n}=\frac{N}{1+N e^{2}}
$$

dimana $\mathrm{n}$ adalah besaran sampel, $\mathrm{N}$ besaran populasi, dan $e$ tingkat kesalahan sampling. Dengan ukuran populasi 356 dan tingkat kesalahan 15\%, diperoleh ukuran sampel sebesar 40 responden.

Data yang dikumpulkan dalam penelitian ini adalah data primer dan data sekunder. Data primer diperoleh melalui wawancara dengan petani sampel menggunakan daftar pertanyaan. Dengan asumsi bahwa modal, bibit, pestisida, dan umur tanaman relatif seragam pengaruhnya terhadap produksi, maka variabel yang digunakan dalam penelitian ini adalah produksi kako, luas lahan, tenaga kerja, pupuk kandang, dan pupuk ponska. Sedangkan data sekunder diperoleh melalui instansi terkait yaitu Badan Pusat Statistik, UPT Kecamatan Rambatan serta literatur yang berkaitan dengan judul penelitian.

Data hasil pengamatan dianalisis dengan menggunakan metode deskriptif untuk menjawab tujuan pertama dan analisis regresi dengan fungsi produksi Cobb Douglass untuk menjawab tujuan kedua. Untuk memudahkan pendugaan terhadap fungsi Cobb Douglass, fungsi tersebut dirubah menjadi bentuk regresi linear berganda dengan logaritma natural terhadap kedua ruas fungsi, yakni:

$$
\operatorname{Ln} Y=\operatorname{Ln} a+b_{1} \operatorname{Ln} X_{1}+b_{2} \operatorname{Ln} X_{2}+b_{3} \operatorname{Ln} X_{3}+b_{4} \operatorname{Ln} X_{4}+u
$$

dimana:

$$
\begin{aligned}
\mathrm{Y} & =\text { Produksi kakao }(\mathrm{kg}) \\
\mathrm{X}_{1} & =\text { Luas lahan }(\mathrm{ha}) \\
\mathrm{X}_{2} & =\text { Tenaga kerja }(\mathrm{HKP}) \\
\mathrm{X}_{3} & =\text { Pupuk kandang }(\mathrm{kg}) \\
\mathrm{X}_{4} & =\text { Pupuk ponska }(\mathrm{kg}) \\
\mathrm{b}_{1} & =\text { koefisien pendugaan luas lahan } \\
\mathrm{b}_{2} & =\text { koefisien pendugaan tenaga kerja } \\
\mathrm{b}_{3} & =\text { koefisien pendugaan pupuk kandang } \\
\mathrm{b}_{4} & =\text { koefisien pendugaan pupuk ponska } \\
\mathrm{u} & =\text { residual }
\end{aligned}
$$

Model regresi berganda disebut sebagai model yang baik jika model tersebut memenuhi asumsi normalitas dan terbebas dari asumsi-asumsi klasik statistik baik normalitas, multikolinearitas, autokorelasi maupun heteroskedastisitas (Nugroho,2005). Untuk itu sebelum menggunakan analisis regresi berganda terlebih dahulu dilakukan uji-uji asumsi klasik berupa uji normalitas, uji multikolinearitas, uji heteroskedastisitas, dan uji autokorelasi, kemudian dilanjutkan dengan pengujian hipotesis berupa uji $\mathrm{F}$ untuk pengujian kebermaknaan semua variabel bebas scara bersama-sama, uji $t$ untuk menguji kebermaknaan masing-masing variabel bebas, dan analisis koefisien determinasi $\left(\mathrm{R}^{2}\right)$ untuk mengetahui keandalan persaaan regresi.

\section{HASIL DAN PEMBAHASAN}

\section{Usaha Tani Kakao Nagari Balimbing}

Usaha tani kakao di Nagari Belimbing Kabupaten Tanah Datar, mulai dari persiapan lahan, penanaman, pemeliharaan, sampai panen dan pasca panen rata-rata menggunakan tenaga kerja dalam keluarga, hanya beberapa yang menggunakan tenaga kerja kerja luar keluarga, itupun dilakukan pada waktu penyiangan saja. Petani responden rata-rata menggunakan pupuk kandang dan pupuk ponska dalam 
budidaya kakao, dan ada beberapa petani yang sama sekali tidak menggunakan pupuk dalam budidaya kakaonya. Tidak ada petani yang menggunakan pestisida dalam melakukan pemberantasan hama dan penyakit. Mereka hanya menggunakan cara manual saja yaitu dengan pemetikan dan pemangkasan secara teratur untuk menghindari penularan penyakit pada buah yang lain. Pemanenan dilakukan sebanyak sekali dalam seminggu dan hasil panen diproses sampai diperoleh biji kakao dari buahnya, dilanjutkan dengan fermentasi selama 4 hari dan penjemuran biji selama 2 hari. Hasil yang telah diproses dari pengolahan pasca panen tersebut dijual ke pasar atau dijemput oleh pedagang pengumpul.

\section{Faktor-faktor yang Mempengaruhi Produksi Kakao Rakyat di Nagari Balimbing}

Untuk mengetahui faktor-faktor yang mempengaruhi produksi kakao, terlebih dahulu dilakukan beberapa uji asumsi klasik, kemudian dilanjutkan dengan uji pengaruh variabel secara serempak, secara individual, dan keterandalan model regresi.

\section{Uji Asumsi Klasik}

Pada uji asumsi klasik dilakukan 4 pengujian, yaitu uji normalitas, uji multikolinearitas, uji heteroskedastisitas, dan uji autokorelasi. Uji normalitas dilakukan untuk megetahui apakah data residual pada model memenuhi asumsi kenormalan. Menurut Priyatno (2010:187) metode Kolmogorov Smirnov merupakan salah uji normalitas dengan menggunakan distribusi kumulatif sehingga dapat diketahui apakah suatu data menyebar normal atau tidak. Dari hasil pengujian diperoleh nilai signifikansi sebesar 0,61 lebih besar dari 0,05 sehingga dapat disimpulkan bahwa data yang diuji adalah berdistribusi normal.

Uji multikolinearitas pada suatu model dapat dilihat dari beberapa hal yaitu, jika Variance Inflation Factor (VIF) tidak lebih dari 10 dan jika tolerance tidak kurang dari 0,1 maka model dapat dikatakan terbebas dari multikolinearitas (Santoso, 2000: 360). Hasil pengujian menunjukkan bahwa faktor pupuk kandang dan pupuk ponska mengalami masalah multikolineritas. Untuk mengatasi masalah tersebut kedua variabel dikeluarkan dari persamaan karena tidak memenuhi syarat, sehingga hanya variabel luas lahan dan tenaga kerja /HKP yang dimasukkan kedalam persamaan.

Uji heterokedastisitas dilakukan untuk menguji apakah didalam sebuah model regresi terjadi ketidaksamaan varians dari residual satu pengamatan ke pengamatan lain (Priyatno, 2010: 203). Cara menguji ada tidaknya heteroskedasitisitas pada suatu model dapat dilakukan dengan menggunakan Uji Park, yaitu dengan meregresikan variabel independen dengan nilai logaritma residual yang telah dikuadratkan. Hasil dari Uji Park menunjukkan secara statistik tidak signifikan (tingkat signifikansi > 0,05 ) berarti tidak terjadi heteroskedastisitas.

Model regresi yang mengalami gejala autokorelasi memiliki standart error yang sangat besar. sehingga kemungkinan besar model regresi menjadi tidak signifikan (Ghozali, 2007). Uji autokorelasi dilakukan dengan Uji Run Test dan didapatkan hasil uji yang menunjukan nilai signifikan sebesar 0,149. Karena nilai signifikansi > 0,05 maka disimpulkan bahwa tidak terjadi autokorelasi antar nilai residual dalam model tersebut.

\section{Uji Pengaruh Variabel Bebas}

Variabel bebas yang digunakan dalam analisis regresi adalah variabel-variabel yang telah memenuhi persyaratan setelah melalui pengujian asumsi klasik. Keandalan persamaan regresi dilihat dari nilai koefisien determinasi $\left(\mathrm{R}^{2}\right)$. Koefisien determinasi berguna untuk mengukur seberapa besar porsi variasi variabel dependen dapat dijelaskan oleh variasi variabel-variabel independen Widarjono, 2007: 71). Hasil analisis regresi menunjukkan bahwa nilai $\mathrm{R}^{2}$ paling besar adalah 1 dan paling kecil adalah. Bila $\mathrm{R}^{2}$ kecil sekali mendekati nilai 0 maka garis regresi tidak dapat digunakan untuk membuat ramalan variabel dependen, sebab variabel-variabel yang dimasukkan kedalam persamaan regresi tidak mempunyai pengaruh terhadap varians variabel dependen.

https://doi.org/10.25077/joseta.v1i1.13 
Ringkasan hasil analisis regresi untuk variabel-variabel yang digunakan dalam persamaan yaitu variabel luas lahan dan tenaga kerja dengan menggunakan SPSS dapat dilihat pada Tabel 1. Dalam hal ini pengaruh variabel luas lahan dan tenaga kerja terhadap jumlah produksi kakao diperoleh nilai $\mathrm{R}^{2}$ sebesar 0,982 artinya variasi variabel bebas menjelaskan variasi produksi kakao di Nagari Belimbing sebesar $98,2 \%$. Sedangkan sisanya sebesar $1,8 \%$ dijelaskan oleh variabel-variabel lain yang belum dimasukkan kedalam model, sehingga dengan $\mathrm{R}^{2}$ tersebut dapat dinyatakan bahwa model yng digunakan dapat menjelaskan hubunganya antara variabel dependen dengan variabel independen, atau model regres tersebut cukup dapat diandalkan.

Tabel 1: Ringkasan Hasil Analisis Regresi

\begin{tabular}{|llllll|}
\hline Model & R & R Square & $\begin{array}{l}\text { Adjusted R } \\
\text { Square }\end{array}$ & $\begin{array}{l}\text { Std. Error of } \\
\text { the Estimate }\end{array}$ & $\begin{array}{l}\text { Durbin- } \\
\text { Watson }\end{array}$ \\
\hline 1 & $.991^{\mathrm{a}}$ & .982 & .981 & .11269 & 1.889 \\
\hline
\end{tabular}

Pengaruh variabel bebas, yaitu luas lahan dan tenaga kerja, secara bersama sama terhadap variabel terikat yaitu produksi kakao diuji dengan uji $\mathrm{F}$ melalui tabel analisis ragam. Hasil perhitungan dalam tabel analisi ragam dapat dilihat pada Tabel 2.

Tabel 2: Hasil Uji F

\begin{tabular}{|llllll|}
\hline \multicolumn{1}{|c}{ Model } & \multicolumn{1}{c}{$\begin{array}{c}\text { Sum of } \\
\text { Squares }\end{array}$} & Df & Mean Square & F & Sig. \\
\hline Regression & 25.103 & 2 & 12.551 & 988.402 & $.000^{\mathrm{a}}$ \\
Residual & .470 & 37 & .013 & & \\
Total & 25.573 & 39 & & & \\
\hline
\end{tabular}

Dari hasil regresi diatas terlihat pengaruh luas lahan $\left(\mathrm{X}_{1}\right)$ dan curahan tenaga kerja $\left(\mathrm{X}_{2}\right)$ terhadap jumlah produksi kakao (Y) diperoleh nilai $\mathrm{F}$ tabel dengan taraf nyata 0,05 dan derajat bebas 2,37 sebesar 3,24 sedangkan $\mathrm{F}$ hitung 988.402 sehingga $\mathrm{F}$ hitung $>\mathrm{F}$ tabel $(988.402>3,24)$, dan nilai signifikan pada tabel adalah sebesar 0,000 artinya nilai signifikan $<0,05$ yang menunjukkan bahwa variabel independen secara bersama-sama berpengaruh signifikan terhadap variabel terikat.

Untuk melihat pengaruh variabel bebas secara individul digunakn uji t. Hasil uji t dapat dilihat pada Tabel 3. Dari hasil pengujian ini dapat dijelaskan bahwa variabel luas lahan $\left(\mathrm{X}_{1}\right)$ memiliki signifikansi sebesar 0,000 hal ini berarti $\mathrm{H}_{0}$ ditolak karena nilai signifikan $<0,05$ dan $\mathrm{H}_{1}$ diterima, maka hubungan variabel luas lahan $\left(\mathrm{X}_{1}\right)$ terhadap produksi kakao $(\mathrm{Y})$ adalah signifikan. Variabel tenaga kerja $\left(\mathrm{X}_{2}\right)$ memiliki signifikansi sebesar 0,003 hal ini berarti $\mathrm{H}_{0}$ ditolak karena nilai signifikan $<0,05$ dan $\mathrm{H}_{1}$ diterima maka pengaruh variabel curahan tenaga kerja $\left(\mathrm{X}_{2}\right)$ terhadap produksi kakao $(\mathrm{Y})$ adalah signifikan.

Tabel 3 : Hasil Uji t

\begin{tabular}{|llllllll|}
\hline Model & \multicolumn{2}{c}{$\begin{array}{c}\text { Unstandardized } \\
\text { Coefficients }\end{array}$} & $\begin{array}{c}\text { Standardized } \\
\text { Coefficients }\end{array}$ & & \multicolumn{2}{c|}{ Collinearity Statistics } \\
& $\mathrm{B}$ & Std. Error & Beta & $\mathrm{T}$ & Sig. & Tolerance & VIF \\
\hline (Constant) & 4.196 & .825 & & 5.086 & .000 & & \\
LNX1 & .858 & .057 & .828 & 14.998 & .000 & .163 & 6.139 \\
LNX2 & .534 & .168 & .175 & 3.170 & .003 & .163 & 6.139 \\
\hline
\end{tabular}




\section{Faktor-faktor Yang Mempengaruhi Produksi Kakao}

Berdasarkan hasil pendugaan parameter dan pengujian koefsisen regresi dapat diketahui bahwa dari empat variabel bebas yang digunakan dalam model ini, hanya dua varoiabel yang signifikan, yaitu luas lahan dan tenaga kerja dengan koefisien regtresi masing-masing sebesar 0,858 dan 0.534, sehingga fungsi Cobb Douglass dari yang diperoleh adalah:

$$
\mathrm{Y}=\mathrm{e}^{4,196} \mathrm{X}_{1}^{0,858} \mathrm{X}_{2}{ }^{0,534}
$$

atau

$$
\operatorname{Ln} Y=4,196+0,858 \ln X_{1}+0,534 \ln X_{2}
$$

Nilai koefisien dari luas lahan adalah sebesar 0,858 dapat dikatakan jika luas lahan naik sebesar 1\% maka produksi kakao akan naik sebesar 0,858 \%. Hasil ini mendukung hasil penelitian Doddy (2009) yang menyatakan bahwa variabel luas lahan berpengaruh signifikan terhadap produksi coklat di Kabupaten Dairi. Sedangkan nilai koefisien tenaga kerja adalah sebesar 0,534 dapat dikatakan jika curahan kerja tenaga kerja naik sebesar $1 \%$ maka produksi kakao juga naik sebesar $0,534 \%$. Kesimpulan ini mendukung hasil penelitian Firman (2013) yang menyatakan bahwa variabel tenaga kerja berpengaruh positif dan signifikan terhadap produksi kakao di Kecamatan Sinjai Selatan Kabupaten Sinjai.

Selanjutnya berdasarkan hasil estimasi produksi kakao di Nagari Balimbing Kabupaten Tanah Datar diperoleh hasil bahwa hasil fungsi produksi berada pada kondisi Increasing Return to Scale karena jumlah koefisisen regresi untuk kedua variabel tersbeut adalah sebesar $0,858+0,534=1,199$. Kondisi Increasing Return to Scale yang berarti bahwa persentase pertambahan kuantitas produksi lebih besar dengan pertambahan faktor produksi luas lahan, curahan tenaga kerja. Setiap penambahan $1 \%$ input cateris paribus akan menyebabkan kenaikan output yang lebih besar dari 1\%. Oleh karena itu pada daerah increasing return to scale keuntungan petani akan selalu bisa ditingkatkan dengan cara menambah input.

\section{KESIMPULAN}

Usaha tani kakao di Nagari Balimbing Kabupaten Tanah Datar merupakan usaha tani rakyat yang ratarata dalam proses budidayanya menggunakan tenaga kerja dalam keluarga mulai dari persiapan lahan sampai pasca panen. Dalam budidaya kakao petani menggunakan pupuk kandang dan pupuk ponska, beberapa petani ada yang tidak menggunakan pupuk. Pemberantasan hama dan penyakit dilakukan dengan cara manual yaitu dengan pemetikan, pemangkasan dan sering melakukan panen. Pemanenan dilakukan sebanyak sekali dalam seminggu dan terhadap biji hasil panen dilakukan fermentasi. Hasil panen yang telah difermentasi dijual ke pasar atau dijemput oleh pedagang pengumpul.

Faktor - faktor yang mempengaruhi produksi kakao di Nagari Balimbing Kabupaten Tanah Datar adalah luas lahan dan curahan tenaga kerja.Sedangkan faktor yang tidak mempengaruhi produksi kakao di Nagari Balimbing Kabupaten Tanah Datar adalah pupuk kandang dan pupuk ponska. Skala usaha produksi kakao berada pada kondisi increasing return to scale yang berarti bahwa persentase pertambahan kuantitas produksi lebih besar dengan pertambahan kuantitas faktor produksi luas lahan dan tenaga kerja.

\section{SARAN}

Kepada para petani agar dapat meningkatkan luas lahan untuk kakao dan sekaligus memelihara dengan baik sesuai dengan pedoman agar dapat mencapai produksi kakao yang maksimal. Curahan tenaga kerja juga harus ditingkatkan oleh petani, terutama curahan tenaga kerja dalam pemeliharaan, karena dengan meningkatnya curahan kerja petani maka kakao akan terawat dan terpelihara dengan baik sehingga dapat menghasilkan produksi kakao dengan kualitas yang baik. Demikian juga perlunya peningkatan perhatian 
yang lebih serius dari pemerintah Nagari Balimbing Kabupaten Tanah Datar terutama Dinas Perkebunan agar lebih aktif dalam memberikan bimbingan/penyuluhan kepada petani kakao tentang cara budidaya coklat yang benar terutama cara pemakaian pupuk yang tepat serta memberikan pengetahuan tentang cara mencegah dan mengatasi tanaman dari serangan hama/penyakit. Dalam kesempatan ini penulis menyarankan kepada peneliti selanjutnya untuk mengidentifikasi variabel-variabel lainnya yang dapat mempengaruhi produksi kakao seperti pemakaian teknologi di bidang pertanian dan lainnya.

\section{DAFTAR PUSTAKA}

Budiono. 2002. Ekonomi mikro seri sipnosis : pengantar ilmu ekonomi No 1. BPFE, Yogyakarta. [BPS] Badan Pusat Statistik Tanah Datar. 2013. Tanah Datar dalam Angka.

[BPS] Badan Pusat Statistik Tanah Datar. 2017. Tanah Datar dalam Angka.

Dinas perkebunan Sumbar, 2009. Laporan Luas Perkebunan Kakao Sumatera Barat. Padang.

Dinas Tanaman Pangan Hortikultura dan Perkebunan Sumbar.2017. Kakao Sebagai Target Besar Pengembangan Di Sumbar.Padang.

Direktorat jendral perkebunan, 2007.Pedoman Teknis Perluasan Tanaman Kakao Tahun 2007. Padang.

Doddy, 2009. Analisis Faktor-Faktoryang Mempengaruhi Produksicoklat Dikabuparten Dairi.Medan : Universitas Sumatera Utara.

Firman. 2013. Faktor Produksi Yang Mempengaruhi Produksi Kakao Di Kecamatan Sinjai Selatan Kabupaten Sinjai.

Ghozali, Imam. 2007. Aplikasi Analisis Multivariate dengan Program Spss. Cetakan Keempat. Semarang : Badan Penerbit Universitas Diponegoro.

Kementrian Pertanian. 2016. Outlook Kakao. Jakarta.

Kristanto, Aji SP. 2011. Panduan Budidaya Kakao. Yogyakarta : Pustaka Baru Press.

Nugroho. 2005. Strategi Jitu Memilih Metode Statistic Penelitian Dengan SPSS.Yogyakarta : ANDI.

Priyatno, 2010. 5 Jam Belajar Olah Data Dengan SPSS 19.Yogyakarta : Andi.

Putra, Nasir. 2015. Faktor-Faktor Yang Mempengaruhi Produksi Sector Pertanian Di Propinsi Aceh.

[Puslitkoka] Pusat Penelitian Kopi dan Kakao. 2013.

Santoso. 2012. Panduan lengkap SPSS versi 2.0.Jakarta : PT Alex Media Computindo.

Saputra. 2015. Faktor-Faktor Yang Mempengaruhi Produksi Kakao Di Kabupaten Muaro Jambi.

Soekartawi, 2003.Agribisnis Teori Dan Aplikasinya.Jakarta : PT RajaGrafindo Persada.

Sugiyono. 2015. Metode Peneitian Manajemen. Bandung : Alfabeta.

Widarjono, A. 2007. Ekonometrika, Teori dan Aplikasi Untuk Ekonomi dan Bisnis. Penerbit Ekonisia, Yogyakarta. 